\title{
Evaluation of a lattice structure for a motor holder
}

\author{
Chloé Joffre \\ University of Wolverhampton, Wolverhampton, UK and \\ ESTIA, Bidart, France
}

\begin{abstract}
Purpose - The aim of this research paper is to design a motor holder in order to minimize the weight of the motor and to reduce its vibrations causing noise pollution.

Design/methodology/approach - To meet the requirements of the purpose the use of cellular lattice structures is ideal. Lattice structures ensure both low mass and high strength. Moreover, their absorption properties are relatively interesting concerning the attenuation of vibrations.

Findings - The result of this paper shows that lattice structure can answer to the need of different fields such as aeronautics in the design of lightweight structures which are strong with a low mass. Indeed, the weight of the final structure of the holder is $0.92 \mathrm{~g}$ and its safety factor is 5.1 which met the requirements.

Research limitations/implications - The limitations of the research paper were the RAM capacity of the computer.

Social implications - To minimize the weight of the holder in a patroller or a plane is to reduce the consumption of fuel. Moreover one of the reasons of optimizing the vibrations is to reduce noise pollution.

Originality/value - This paper is directed to students, designers who want to know more about the use of lattice structure and more precisely honeycomb sandwich structure.
\end{abstract}

Keywords Lattice structures, Unit cell, Sandwich structures, Vibrations, Static analysis, Frequency,

Lightweight, Strength, Absorption, Honeycomb, Hexagonal, Holder

Paper type Research paper

\section{Introduction}

The purpose of this assignment is to design the holder of the motor used for the Patroller of Safran Defence. The Patroller structure has high requirements such as the holder of the motor. The motor used is called Rotax 914. The motor can rotate at 10,000 RPM. The main objective of this assignment will be to verify if the use of a lattice structure for the holder of the motor can be optimal and carry out the needs of the support without compromise its strength.

\section{Design}

\subsection{Design of the unit cell}

In order to make the motor holder lighter, the first design chosen was a hexagonal unit cell inspire from honeycomb. The advantage of this unit cell is its low mass, a low volume and a high strength (See Figure 1).

Indeed, honeycomb unit cell are used in fields such as aeronautics for its mechanical properties. This kind of unit cell has an excellent ratio strength/lightness and the presence of angles allows a dissipation of forces through the honeycomb. (Binetruy, 2008)

For a reason of RAM capacity this unit cell was made of a $3 * 3 * 3 \mathrm{~mm}$ cube.

(C) Chloé Joffre. Published in Journal of Intelligent Manufacturing and Special Equipment. Published by Emerald Publishing Limited. This article is published under the Creative Commons Attribution (CC BY 4.0) licence. Anyone may reproduce, distribute, translate and create derivative works of this article (for both commercial and non-commercial purposes), subject to full attribution to the original publication and authors. The full terms of this licence may be seen at http://creativecommons.org/licences/by/4.0/ legalcode

Received 21 December 2020 Revised 8 February 2021 Accepted 8 February 2021

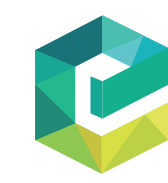

Journal of Intelligent Manufacturing and Special Equipment Vol. 2 No. 2, 2021 pp. $63-74$

Emerald Publishing Limited e-ISSN: 2633-660X p-ISSN: $2633-6596$ DOI 10.1108/JIMSE-12-2020-0019 


\section{JIMSE \\ 2,2}

64

\section{Figure 1.}

Dimensions of the hexagonal unit cell
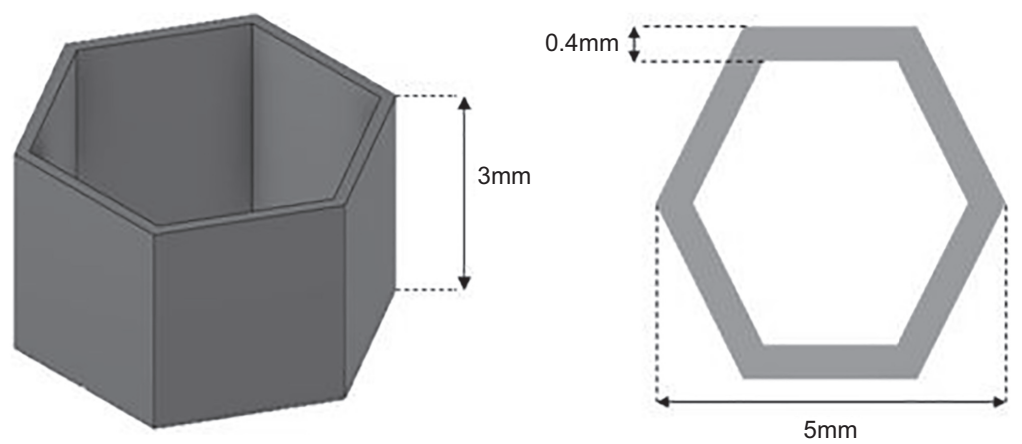

By using this unit cell, the final volume is $7.48 \mathrm{~mm}^{3}$, which corresponds to $27 \%$ of the volume of the cube from which the unit cell is made.

Indeed, the total volume is $27 \mathrm{~mm}^{3}$ and the bulk volume is $7.48 \mathrm{~mm}^{3}$. Hence, the porosity is $73 \%$.

To establish the pertinence of lattice design Maxwell's stability criterion is useful.

The Maxwell's stability criterion, for 3-dimensions unit cell, is given by: $M=b-3 * j+6$, where:

(1) $b$ corresponds to the beams

(2) $j$ corresponds to the joints

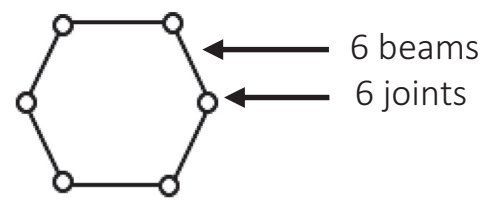

For the hexagonal unit cell there are 6 beams and 6 joints. So, $M=6-3 * 6+6=-6$.

The Maxwell's stability criterion is negative, that is to say, the unit cell obtained is a bending dominated lattice opposed to stretching dominated lattice. Contrary to stretching dominated lattice, which are stiffer, bending dominated lattice are relatively good for energy absorption. (PADT article, 2016)

However, the choice of a hexagonal unit cell, can lead to an issue with the drilling quality of the holder.

So, with the aim of optimizing the holder, to improve the drilling quality and the stiffness, the final design chosen is a unit cell as a Sandwich structure with a honeycomb core (see Figure 2).

As the first unit cell, the unit cell was made of a $3 * 3 * 3 \mathrm{~mm}$ cube. The total volume is $27 \mathrm{~mm}^{3}$ and the bulk volume is $15.14 \mathrm{~mm}^{3}$. Hence, the porosity is $44 \%$.

Considering two plates added, there are now, 14 beams and 10 joints.

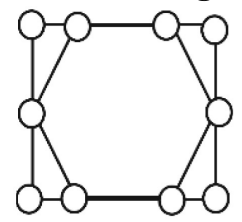

$M=b-3 j+6$, so, $M=14-3 * 10+6=-10$ 
The Maxwell's stability criterion, equals to -10 , is negative so the unit cell is still bending dominated. However, using a Sandwich structure we have a stiffness gain and a good resistance to forces. Indeed, Sandwich structures are of interest for applications that require both rigidity and lightness.

The relevant property of Sandwich structures is that the inertia moment can increase by increasing the thickness of the core structure. The rise of the inertia moment is resulting in the rise of stiffness, while keeping a low mass. (Binetruy, 2008)

The constraint is given by the formula:

$$
\sigma=\frac{M * y}{\lg z}=\frac{M^{*} y}{\frac{t^{3} b}{12}}=\frac{M * y^{*} 12}{t^{3 * b}}
$$

With:

(1) $M$ : Bending moment

(2) $y$ : deformation distance

(3) $t$ : thickness

(4) $b$ : base

So, if the thickness increases the constraint decreases. That the reason why, rigidity can be gained by increasing the thickness and keeping a low mass. The ratio strength/lightness is optimal.

\subsection{Design of the lattice structure}

The dimensions of the designed holder must respect the following settings: (see Figure 3)

The holder is approximately composed of $40 \times 40 \mathrm{~mm}$. The volume for the original support motor with a thickness of $3 \mathrm{~mm}$ is $1227 \mathrm{~mm}^{3}$.

Using the lattice structure, the volume is now $342 \mathrm{~mm}^{3}$. Which corresponds to $27 \%$ of the volume of the holder without lattice structure. The porosity is about $73 \%$ (see Figure 4).

\section{Material and manufacturing choices}

\subsection{Material choice for the holder}

Aluminum is one of the most used materials in the aeronautic field. Indeed, the mechanical properties of aluminum are highly appreciated. On the one hand density of aluminum is low, such as the cost and it is solid but also malleable enough for manufacturing. Furthermore, the impact environmental of aluminum is good because this is a recycle material (Metal supermarket, 2019).

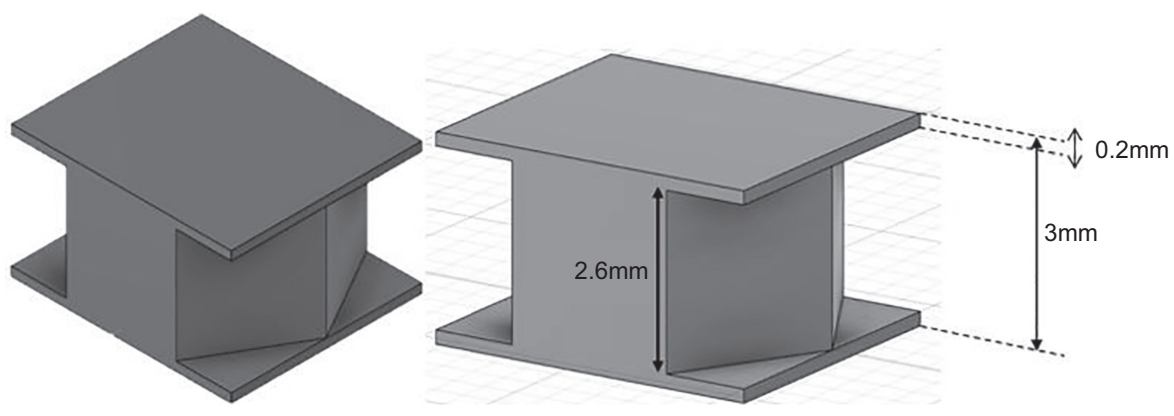

Figure 2.

Dimensions of the final unit cell 


\section{JIMSE 2,2}

66

Figure 3.

Dimensions of the holder
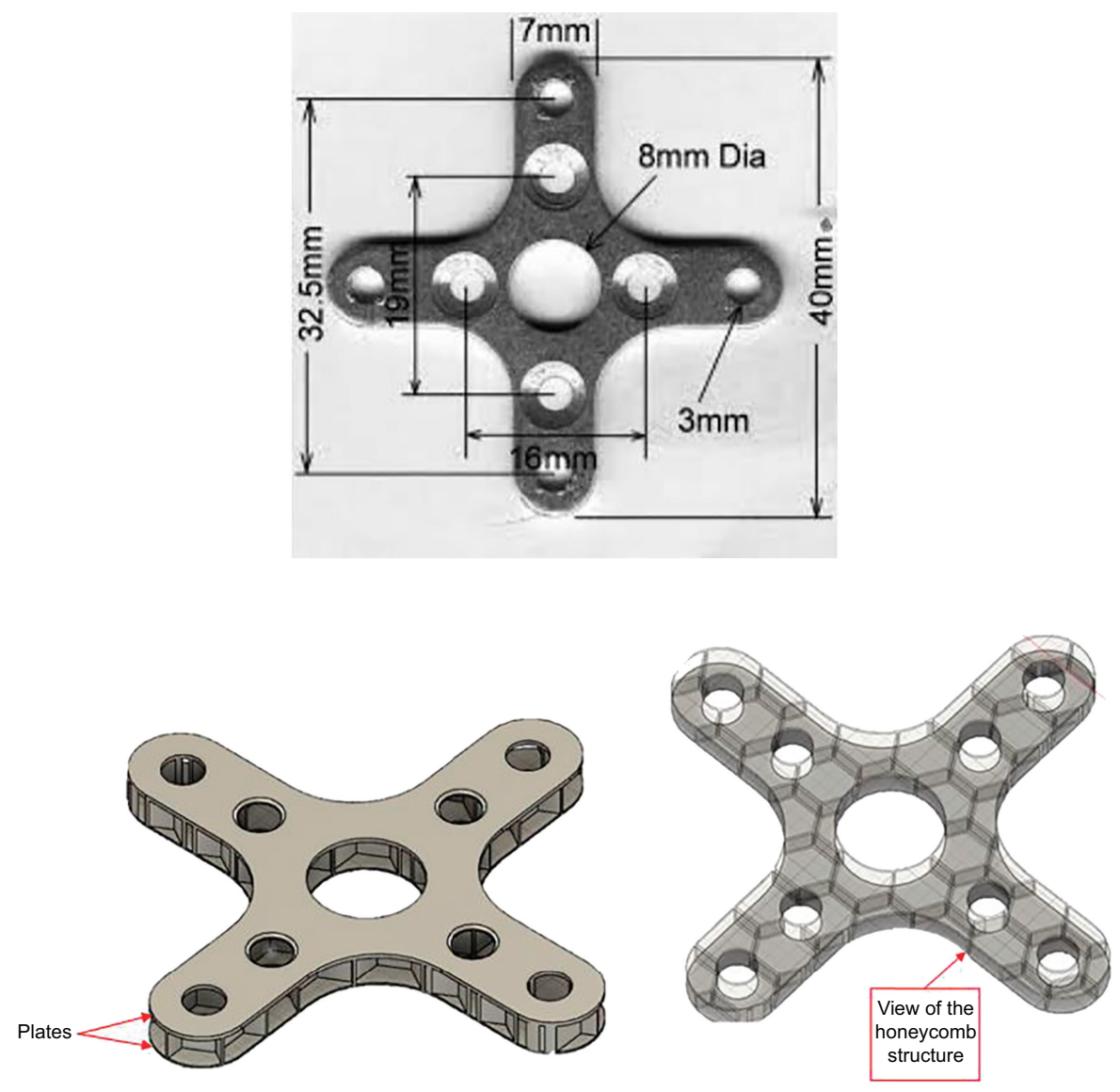

Figure 4.

Motor holder the Sandwich structure and a honeycomb core
Figure 5.

Table of the mechanical properties of aluminum alloys: 6061/7075
On the other hand, in order to answer to demanding requirements in terms of torsional strength, fatigue resistance and hardness, aluminum alloys are the most widely used.

Among these alloys, the most used in aeronautics are aluminum 6061 and aluminum 7075 (CGM Métaux, 2014) (See Figure 5).

Concerning the mechanical properties, as it can be seen on the table, the tensile strength and the yield strength of aluminum 7075 is largely higher than aluminum 6061 .

The lower tensile strength of aluminum 6061 leads to be an easier manufacturable material.

For the lattice structure, we must be aware of fabrication considerations. That's why for the following simulations aluminum 6061 will be chosen.

\begin{tabular}{|c|c|c|c|c|c|}
\cline { 2 - 5 } \multicolumn{1}{c|}{} & Density & $\begin{array}{c}\text { Young's } \\
\text { modulus }\end{array}$ & $\begin{array}{c}\text { Tensile } \\
\text { strength }\end{array}$ & $\begin{array}{c}\text { Elongation at } \\
\text { break }\end{array}$ & $\begin{array}{c}\text { Yield's } \\
\text { strength }\end{array}$ \\
\hline Aluminium 6061 & $2.70 \mathrm{~g} / \mathrm{cm}^{3}$ & $68.9 \mathrm{GPa}$ & $124-290 \mathrm{MPa}$ & $12-25 \%$ & $275 \mathrm{MPa}$ \\
\hline Aluminium 7075 & $2.81 \mathrm{~g} / \mathrm{cm}^{3}$ & $71.7 \mathrm{GPa}$ & $572 \mathrm{MPa}$ & $11 \%$ & $503 \mathrm{MPa}$ \\
\hline
\end{tabular}


For the lattice structure it could be interesting to manufacture it thanks to additive manufacturing.

Indeed, additive manufacturing allows the manufacture of part with complex geometry, it enables saving manufacturing time, significant materials and money (Hao et al., 2011).

However, this choice must be very carefully considered. In fact, due to the small size of the holder accuracy can be hampered. Moreover, aluminum has reflection properties which must be considered in the choice of the additive manufacturing process. Additive manufacturing process includes post processing, such as polishing or heat treatment. These methods must be done with accuracy in order to not damage the lattice structure.

So, in that case, additive manufacturing offers both advantages and disadvantages, which have to be measured and corresponds the requirements of the mechanical behavior expected.

\section{FAE simulation}

Simulations are run on Fusion360. Simulations are necessaries to evaluate the unit cell and the motor holder. As it has been said, the holder must minimize the vibrations and the weight.

Consequently, several simulations will be run:

(1) A vibration analysis for the unit cell

(2) A static analysis and a vibration analysis for the holder

\subsection{Simulation of the unit cell}

The vibration analysis: The aim of this simulation is to verify that the natural frequency of the unit cell and the holder are different from the natural frequency of the motor. Indeed, if the frequencies are the same, the motor will start to resonate and cause damage.

The motor rotates at 10,000 RPM CC. So, to determine the natural frequency:

$1 \mathrm{rpm}=\frac{1}{60} \mathrm{~Hz} \mathrm{so}, f=\frac{10000}{60}=166 \mathrm{~Hz}$

The natural frequency of the motor is $166 \mathrm{~Hz}$, in other words, the unit cell and the holder will answer to the requirement of the assignment if their natural frequencies are not equal to $166 \mathrm{~Hz}$.

To evaluate the unit cell only a vibration analysis will be run.

The first step of the simulation to evaluate the unit cell is to check the mesh.

The mesh of the unit cell is composed of 11,762 Nodes and 5,824 Elements. The mesh seems good to have relevant results for the simulation and does not need refinement (see Figure 6).

4.1.1 Vibration analysis. As it can be seen, the first mode of displacement is for a frequency $f=85220 \mathrm{~Hz}$. (see Figure 7)

This deformation is far superior from $166 \mathrm{~Hz}$, about 514 times greater. This natural frequency is acceptable and appropriate for the requirements of the assignment, in that case the lattice structure on the holder can be performed.

\subsection{Simulation of the lattice structure}

The mesh of the holder is composed 29,104 Nodes and 14,125 Elements approximately 2.5 times the number of elements of the unit cell (see Figure 8).

4.2.1 The static analysis. To prove the concept of design the static analysis is done on the holder.

To evaluate the holder, the force applied on the support must be calculated. When the motor turns the propellers generate a static thrust. Consequently, the static thrust must be determined (see Figure 9). 


\section{JIMSE \\ 2,2}

68

Figure 6.

Mesh of the unit cell

Figure 7.

Vibration analysis of the unit cell
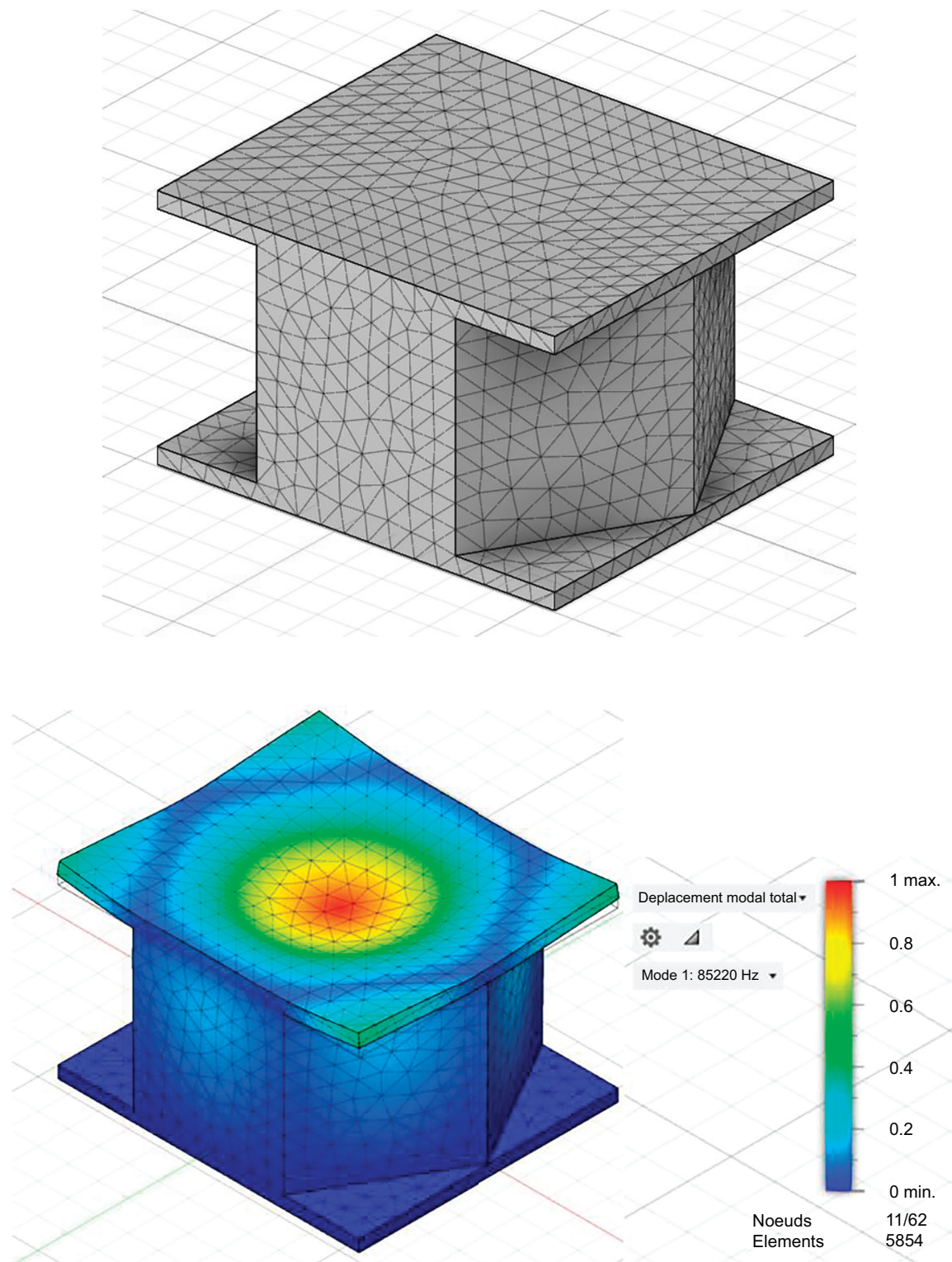

According to the static thrust calculator, the settings required are:

(1) Motor rotates at 10,000 RPM

(2) Diameter of propeller 10"

(3) Pitch of propeller 8"

(4) Number of blades: 2 


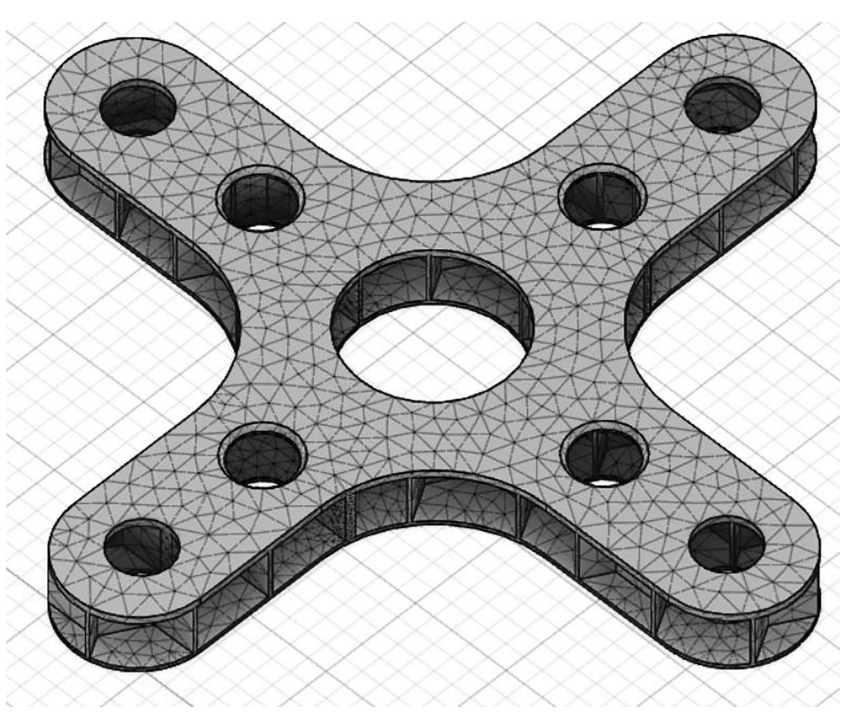

\section{Lattice structure for a motor holder}

69

Figure 8.

Mesh of the motor holder

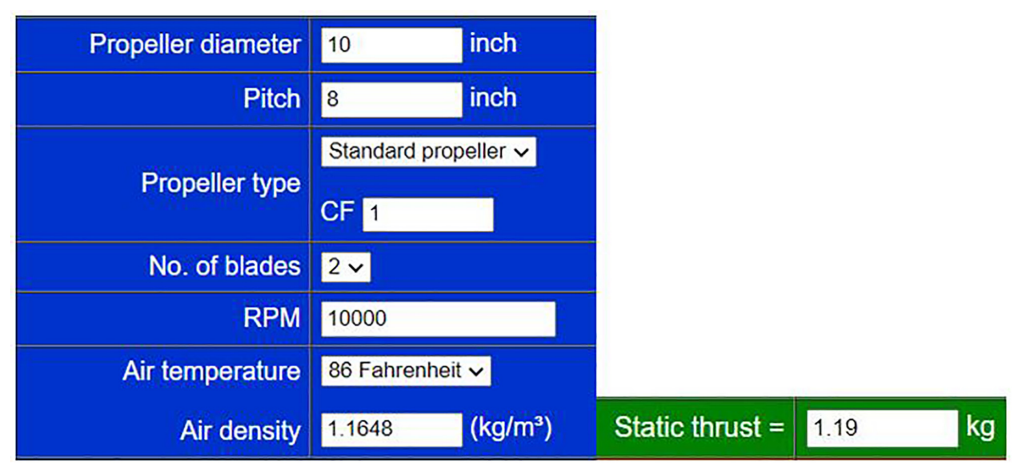

Figure 9.

Calculator to determine the static thrust

The static thrust is equal to $1.19 \mathrm{~kg}$. (static thrust calculator)

The result of the static thrust is in kilograms.

To calculate the static thrust, the formula of Abbott is used. (Zhao et al., 2013)

It is given by:

$$
\text { Thrust }=6.8 * 10^{-5} * \mathrm{RPM}^{2} * D^{3} * P
$$

Where:

(1) $D$ corresponds to the diameter of the propeller in meter $(0.254 \mathrm{~m})$

(2) $P$ corresponds to the pitch of the propeller in meter $(0.2035 \mathrm{~m})$

It is assumed that the static thrust is the only force exerted on the motor, so, according to the fundamental principle of dynamic, to have the force in Newtons $F=$ Thrust $* 9.81$ which gives, the inertia equals to $11.9 \mathrm{~N}$. 
JIMSE 2,2

70

To run the static analysis, the holder must be under constraints.

(1) The inertia $11,9 \mathrm{~N}$

(2) The remote force $2 \mathrm{~N}$ corresponding to the motor weight (200 g)

- X distance: $20 \mathrm{~mm}$

- Y distance: $20 \mathrm{~mm}$

- $Z$ distance: $27.5 \mathrm{~mm}$

(3) The gravity $g=9.81 \mathrm{~m} / \mathrm{s}$

(4) Aluminum 6061

Results:

Stress constraint is equal to 53.65 MPa. (see Figure 10)

This stress constraint is maximal around the four chamfered holes due to the geometry and around the hole in the middle of the holder. Indeed, it is in the center that the workpiece is subjected to the most stress, which is why the stress is greatest. Moreover, this stress passes through the Sandwich structure.

In order to improve the distribution of this stress we can reduce the size of the unit cells, which was not possible for a reason of ram capacity.

The displacement of the holder is equal to $D=4.6 \times 10^{-3} \mathrm{~m}$. This low displacement is due to rigidity of the holder (see Figure 11).

The safety factor is equal to 5.126, which is a very good safety factor in the field of aeronautics whose criticality is excessively important (see Figure 12).

The yield strength of the material must be equal to:

$$
\text { Yield strength aluminium }=\text { safety factor } * \text { stress constraint }=273 \mathrm{MPa}
$$

The yield strength of the aluminum 6061 is equal to $276 \mathrm{MPa}$ which corresponds to yield strength required.

4.2.2 Vibration analysis. The first mode of displacement of the holder is equal to $9628 \mathrm{~Hz}$ (see Figure 13).

Figure 10.

Stress analysis on the holder

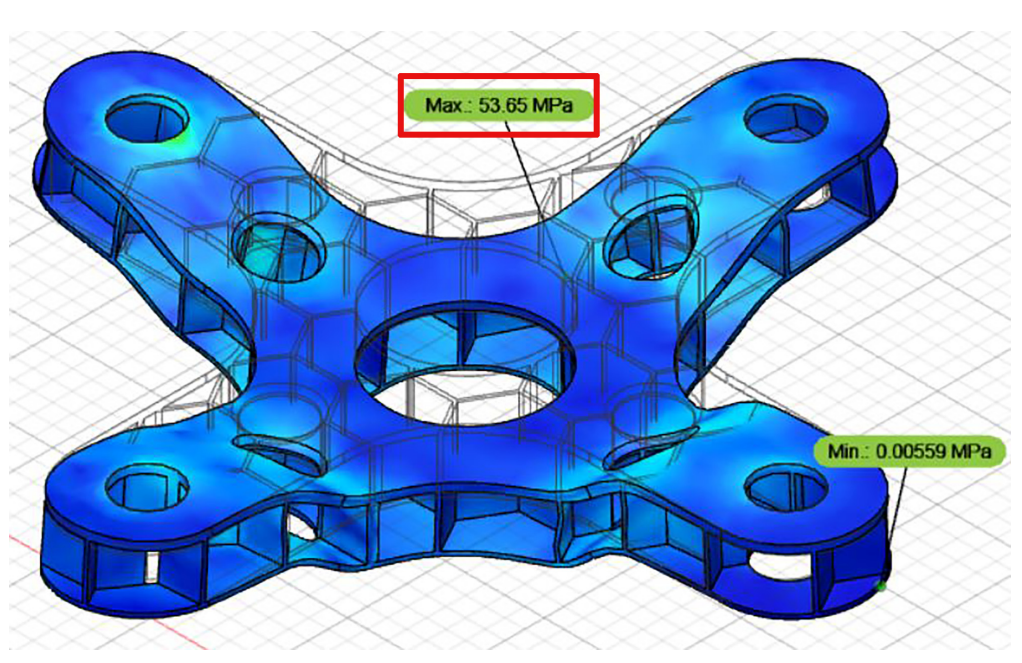




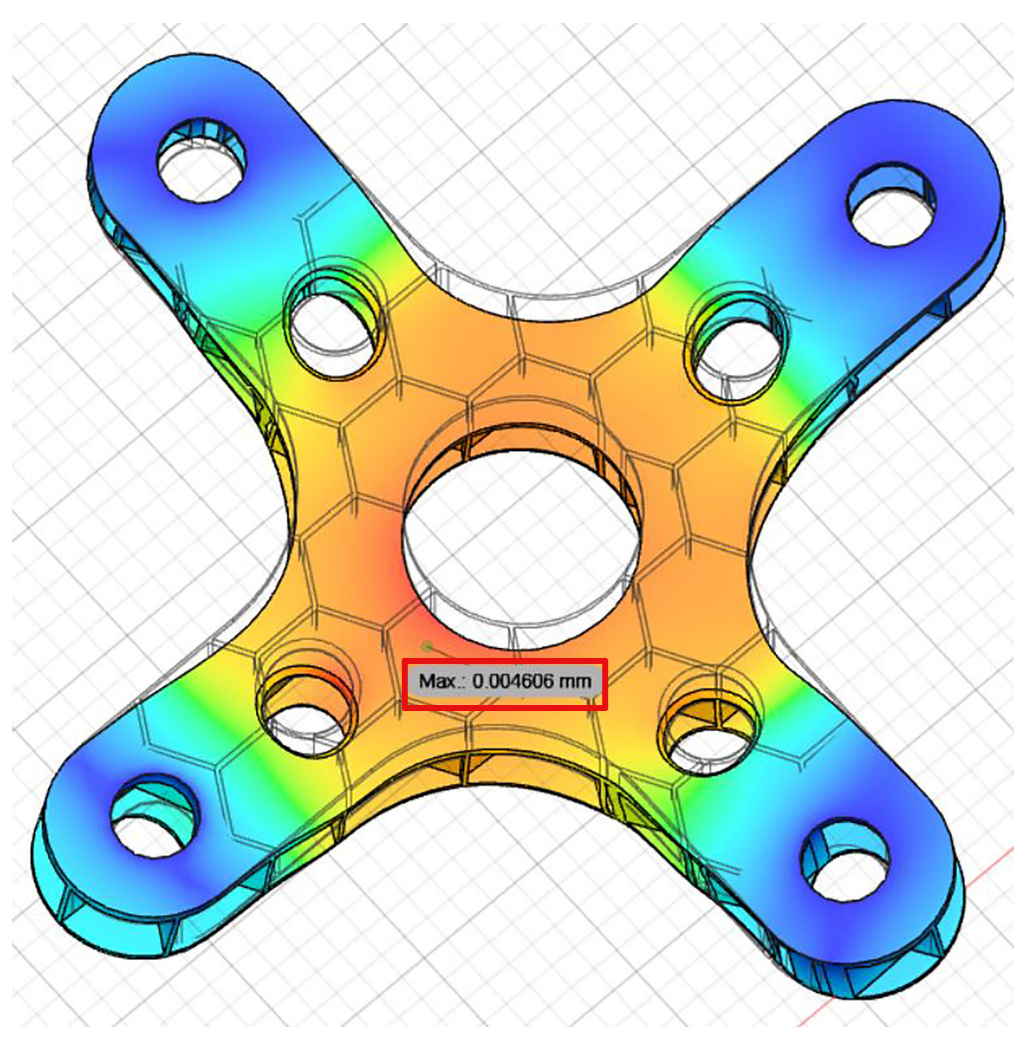

Lattice structure for a motor holder

Figure 11.

Evaluation of the displacement

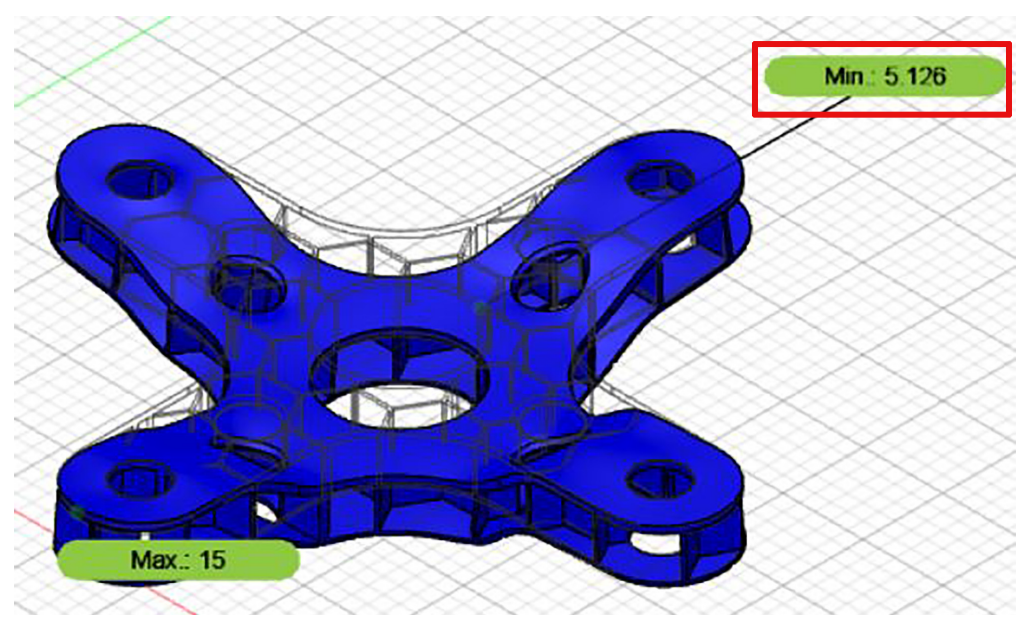

Figure 12. Static analysis of the holder 


\section{JIMSE 2,2}

\section{2}

Figure 13.

Vibration analysis of the holder

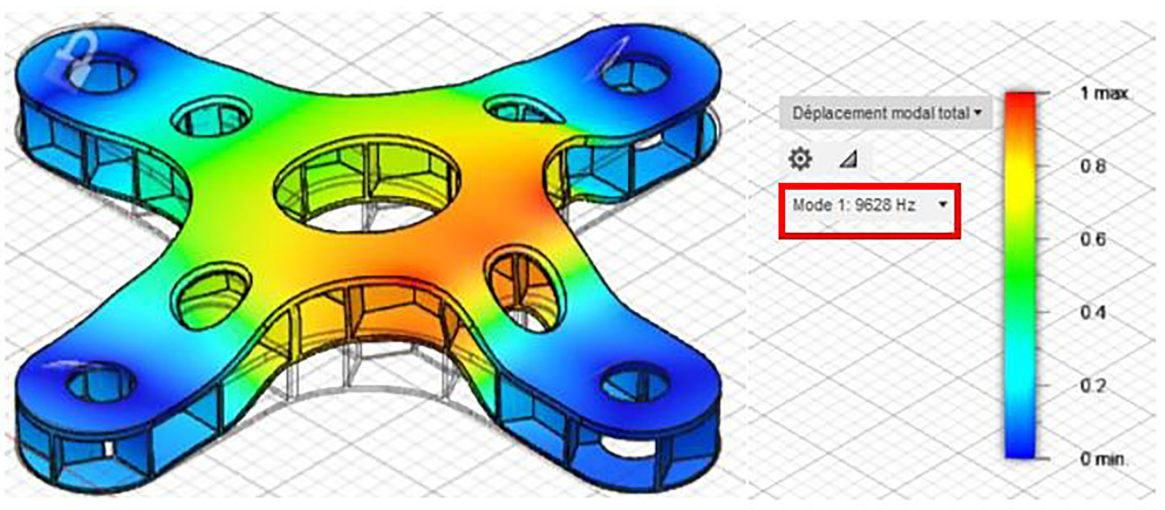

This natural frequency is far superior from $166 \mathrm{~Hz}$ and it is highly appropriate for the holder.

Moreover, Figure 14, shows good agreement. All the frequencies are different from $166 \mathrm{~Hz}$ (see Figure 15).

\subsection{Comparison and optimization}

The static and the vibration analysis confirms that the use of a lattice structure is appropriate for the holder. Consequently, by using this method the holder is optimized and we can measure the optimization by determining the mass reduction and the volume reduction.

The material use is Aluminum 6061 with a density of $2.7 \mathrm{~g} / \mathrm{cm}^{3}$, that is to say, $2.7 * 10^{-3} \mathrm{~g} /$ $\mathrm{mm}^{3}$ and the volume of the holder is $342 \mathrm{~mm}^{3}$ (precise where it comes from). The mass of the new holder can be calculated:

$$
m=\rho * V=0.0027 * 342=0.92 g<1 g
$$

The mass of the new holder is much lighter, and it is under $1 \mathrm{~g}$ which fulfills the requirements.

\section{Evolution of the frquency $(\mathrm{Hz})$ for 12 modes deformation}

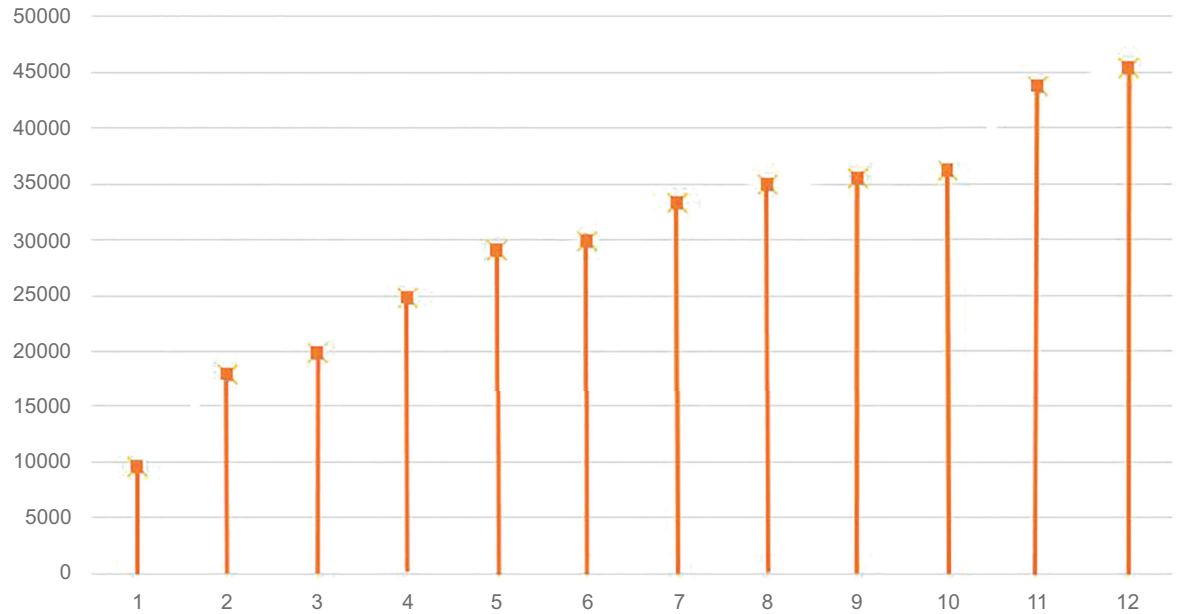

Figure 14.

Frequencies of the 12 modes of deformation of the holder 


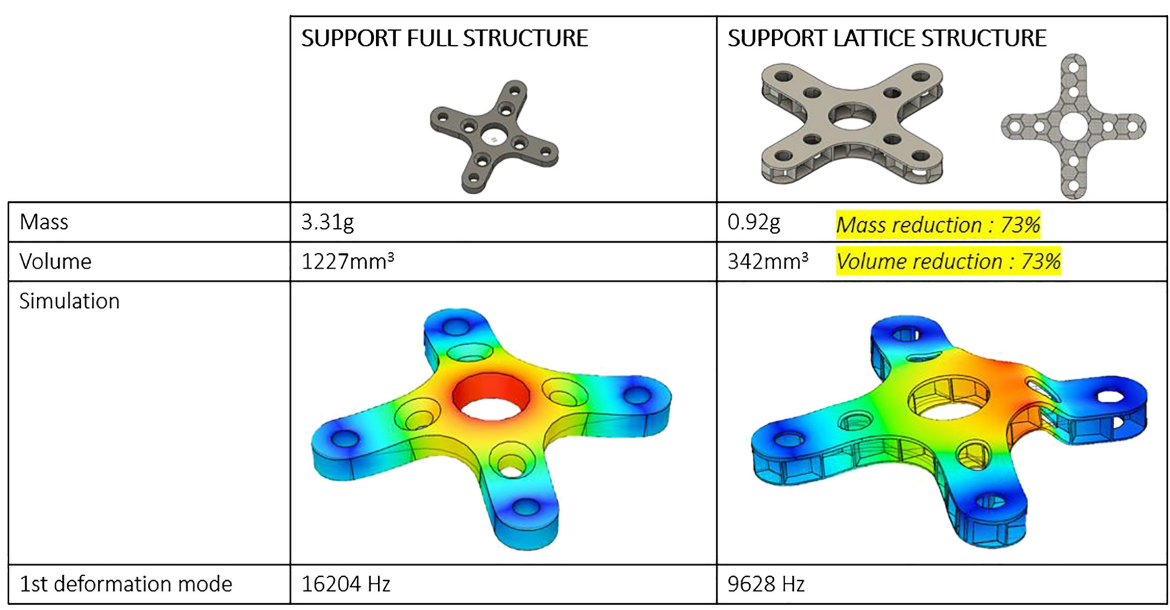

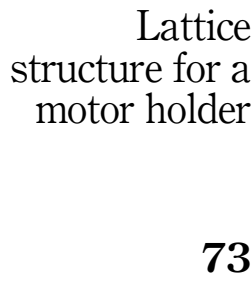

Figure 15

Comparison between the support in a full structure and the support with a lattice structure

\section{Discussions and conclusions}

\section{(1) Overall Results}

The results obtained showed that the choice to design the holder and using a lattice structure is a good method. In fact, the desire to have a lightweight structure, which support and optimize the vibration, is fulfilled thanks to the lattice structure. Moreover, the honeycomb sandwich structure shows that both static and vibration analysis are carried out.

\subsection{Conclusion}

As it has been seen design of emerging tools plays a key role for designing new lightweight structures and it stills improving.

The holder motor is important in the structure of the Patroller. So, designing it with a lattice structure is a new approach which must met the requirements. It has been proven that the lattice structure used for the holder is successful and fulfilled all the requirements for the support.

Lattice structures are increasingly used and machined thanks to additive manufacturing, which offers possibilities for the creation of complex geometries.

\section{References}

Binetruy, C. (2008), "Structures sandwiches", available at: https:/www.techniques-ingenieur.fr/basedocumentaire/materiaux-th11/materiaux-composites-presentation-et-renforts-42142210/ structures-sandwiches-am5141/interet-des-sandwiches-am5141niv10001.html\#: :text=Les \% 20sandwichs $\% 20 \mathrm{pr} \% \mathrm{C} 3 \%$ A9sentent $\% 20$ un $\%$ 20int $\%$ C3 $\%$ A9r $\%$ C3 $\%$ AAt, $) \% 2 C \% 20$ qui $\%$ 20maintient $\%$ 20leur $\% 20 \% \mathrm{C} 3 \%$ A9cartement.

CGM Métaux (2014), “Aluminium pour l'aéronautique”, available at: https://www.cgmetaux.com/ aluminimum-pour-laeronatique/.

Hao, L., Raymont, D., Yan, C., Hussein, A. and Young, P. (2011), "Design and additive manufacturing of cellular lattice structures", available at: https:/www.researchgate.net/publication/ 264955236_Design_and_additive_manufacturing_of_cellular_lattice_structures. 
JIMSE

2,2
Metal Supermarket (2019), "What are the differences between 6061 and 7075”, available at: https:// www.metalsupermarkets.com/differences-6061-and-7075-aluminum/.

PADT (2016), "Classification of cellular solids (and why it matters)", available at: https://www.padtinc. $\mathrm{com} / \mathrm{blog} / \mathrm{classification-of-cellular-solids-and-why-it-matters/.}$

Static thrust calculator", available at: http://godolloairport.hu/calc/strc_eng/index.htm.

Zhao, H., Liu, K. and Yu, X. (2013), "Extract from 'analysis of propeller static thrust estimation method", available at: https://www.scientific.net/AMM.397-400.475.

\section{Further reading}

Sakar, G. and Bolat, F.C. (2015), "The free vibration analysis of honeycomb sandwich beam using 3D and continuum model", available at: https:/www.researchgate.net/publication/303312140_The_ Free_Vibration_Analysis_of_Honeycomb_Sandwich_Beam_Using_3D_and_Continuum_Model.

\section{Corresponding author}

Chloé Joffre can be contacted at: C.Joffre@wlv.ac.uk 